\title{
Impact of Role Conflict, Role Balance on General Well-Being with Students Who Work
}

\author{
${ }^{1}$ Abdul Waheed, ${ }^{2}$ Sadia Malik \\ ${ }^{1}$ Department of Psychology, University of Sargodha, Pakistan \\ ${ }^{2}$ Lecturer, (Department of Psychology, University of Sargodha, Pakistan
}

\begin{abstract}
The objective of this study was to determine the impact of role conflict, role balance on general wellbeing among working students of Sargodha University of Sargodha. This research investigated the process by which role balance, role conflict are linked with a student's general well being. The information and data were collected from a sample of 80 university students (17-35 years) 43 were male and 37 were female had full-time and part-time job. Pearson Product correlation showed that Role-ease was positively linked with well-being, SIW was positively linked with well-being; WIS was negatively linked with well-being. Consequences supported the planned intangible model. The findings of this study may be beneficial for educational psychologist, counselors administrators policy makers, to keep these findings under consideration while taking some steps or planning something.
\end{abstract}

Keywords: General well-being, Impact, Role conflict, Role balance, working students.

\section{Introduction}

The expenses of education are increasing day by day. Many parents of students cannot afford the expenses of whole education. The scholarships are highly competitive. The educational loans are not sufficient to meet the cost of whole education. So, it is common in the students to engage in paid work. There are two categories of working students, one who engaged in full time paid work and the others are engaged in part time job. These working students often face difficulty to give fully attention to their job and study at a time. Their role conflict between work and study come in the shape of absenteeism, strain, stress and even in turn over.

\subsection{Well-being}

Well-being is simplest level is being about personal happiness - feeling good and living safely and healthily. A lot of Researches had developed models to predict how work and family influenced on the wellbeing. Buda and Lenaghan (2005) studied the well-being of college students which is linked with time stressors. Edward and Rothbard (2000, p. 85) "examined how the comparison of work and family experiences to the person's values relates to stress and well-being. Their aim to find out why different people in the same condition faced different levels of stress. Friedman and Greenhaus (2000) found that short of time was not the main source of work family conflict (rather it was due to interference of work into the family domain or family or family domain into the work). Many researchers found the relationship between the personality traits and the work family conflict such as aggressive was (Lightdale and Prentice, 1994) and negative effectively (Carlson, Bruck and Allen, 2003). Therefore in current study we examined the relationship of role-conflict, role-balance and General-wellbeing of working students.

\subsection{Role Balance}

Role balance is completing demands of life in time in different roles of personal lives, which is based on the working students experience when they were involved in numerous roles (such as, study and part time and full time job). Here we divided the role balance in two components such as role over load (Depletion argument). And other was role ease (Enrichment argument). These two measures could be interpreted by the score of Role balance, when the scores of Role balance were low, it was assumed to role over load. If the role balance score was high, it was assumed to role ease, both of the scores (low and high scores of role balance) were correlated. It was a systematic outcome that role ease generated role balance and lack of role balance generated role overload.

\subsection{Role Conflict}

Role conflict can be defines as "it is the measure of experienced pressure of a person in which one role that was unable to get along within another role (Kopelman, et al., 1983). It could occur due to lot of reasons, just like degree of responsibility (Glowinkowski and Cooper, 1986; Cooper and Cartwright, 1994 ). Mistrust of coworkers, poor communication, poor psychological well-being and low job satisfaction (Summarized by Cooper and Cartwright in 1994). Behavior type (Gaster, et al., 1984). In our study, Role conflict could occur 
due to School interface with work (SIW) or due to Work interface with school (WIS). Many researches had found that Role conflict could occur after the Role over load or role strain. SIW type of conflict experienced by students would expect towards Role ease and lending support for the enrichment argument, but WIS type of conflict experienced by students would result in the shape of Role over load. However, previous researches explained that job work was an instrument in achieving a college degree.

\section{Hypothesis:}

The first hypothesis of our study was "The role balance (role ease) will be positively linked with the student's well-being". The second hypothesis of our study was "School interface with work will be positively linked with the student's well-being" and the third hypothesis was "Work interface with school will be negatively linked with the student's well-being".

\section{Method}

\section{1 sample}

A purposive convenient sampling technique was used for the collection of required data. Total numbers of working students were 80 .

The demographic characteristics of the sample are given below

Insert Table 1 here

\subsection{The General Well-Being Scale}

\section{Instruments}

The scale was developed by McDowell and Newell (1987). The lowest well-being scale scores were 14 and the highest scores were 70. The SD of well-being was 8.33and Cronbach's alpha was .69 . The reliability and validity of the General well-being scale has been supported in a lot of studies (McDowell and Newell, 1987). 18 items of well-being gives a calculation of overall well-being of an individual.

\subsection{SIW and WIS Scale}

The inter-role conflict, physical and psychological health problems occur when the graduate students cannot cope with the stress. Physical health problems linked with the stress like headaches (Deckro, Ballinger, Hoyt, \& Wilcher, 2002; Duenwald, 2002); burnout (Neumann, FinalyNeumann, \& Reichel, 1990; Vaez \& Laflamme, 2003; Zalenski, Levey-Thors, \& Schiaffino, 1998; Bruce, Conaglen, \& Conaglen, 2005; Jenkins \& Elliot, 2004; Maslach, Schaufeli, \& Leiter, 2001; Peiro, Gonzalez-Roma, Tordera \& Manas, 2001). upset stomach (Duenwald, 2002); sleep disturbances (Deckro, Ballinger, Hoyt, \& Wilcher, 2002; Duenwald, 2002; Hudd, Dumlao, Erdmann-Sager, Murray, Phan, Soukas, et al, 2000). And Psychological health problems just like anxiety attacks (Duenwald, 2002), depression (Dixon \& Reid, 2000; Frazie(Deckro, Ballinger, Hoyt, \& Wilcher, 2002; Duenwald, 2002); Frazier \& Schauben, 1994; Geraghty, 1997). 3 items scale, School interface with work was associated with student's role ease and role conflict with his/her work and study. 3 items, Work interface with school associated with student's role ease and role overload. Both scales used 5-point Likert scales rated from strongly disagree to strongly agree. The alpha reliability coefficient of WIS was 0.53 and 0.40 for SIW.

\subsection{Role Balance Scale}

Role balance defined as "the lower level role over load relates to role ease" (Marks \& MacDermid, 1996). Role balance/role ease was determined by using four items scale developed by (Marks, Huston, Johnson and MacDermid (2001). Their ratings based upon the 5 point Likert scale ranges from strongly disagree to strongly agree. For example, "Nowadays, I seem to enjoy every part of my life equally well." the lowest score of role balance was 4 and highest was 20 . The alpha reliability level is 0.53

\section{Research design and Procedure}

A survey method was used as a research design. Working students selected from the different department of university of Sargodha. Student's participation was volunteer in our study.

It was important to collect the data from working students in this study, for this purpose data were collected from the Economics department, Psychology department and Information technology Department University of Sargodha. After taking permission from the relative Head of the departments, Questionnaires were given the working students; all participants did not receive any incentive to participate. Details of instruction were delivering to the participants by the author. This included assurance of anonymity. The time for completion of the survey was approximately 20-25 minutes. 


\section{Results}

The data of the study were analyzed through the Statistical Package for Social Sciences (SPSS) $17 \mathrm{~V}$. Various statistical techniques such as co-relation; simple linear regression and ANOVA were applied in order to test the hypotheses of the study. Psychometric Properties of four measures, work interface with school, School interface with Work Questioners, Role Balance Scale and General well-being questioners were computed.

\section{Insert Table 2 here}

Table 2 indicates that Work Inter Face with School Questionnaire is significant and reliable. Its reliability is $(\alpha$ $=.53)$. The School Inter Face with Work Scale $(\alpha=.40)$ which is low reliability due to less items of the scale and the small sample size. The role balance scale $(\alpha=.53)$. Whichis also a low significant reliable due to small sample size and less number of items. General Well Being Scale is found a significant reliability $(\alpha=.69)$

\section{Insert Table 3 here}

Table 3 indicates that there is a significant co-relation between work interfaces with school and school interfacewith work $(r=.45, p<.01)$. Work inter face with School and Role balance were found to be significant but in negative direction $(r=-.26, p<.05)$. There is no significant relationship between work interface with Schooland General Wellbeing $(r=-.175, p>.05)$. Here School interface with work there is no significant co relation between Role balance and General Well Being but Role balance positively correlate with the General Wellbeing $(r=.48, p<.01)$.

\section{Insert Table 4 here}

Table 4 indicates that, The result on regressing the four independent variables against relation to general wellbeing are shown in the above table. $\mathrm{R}(.23)$ is the correlation of the three independent variables with the general well-being after all the inter-correlations. The $\mathrm{R}$ square (.23) indicates that the model is $23 \%$ acceptable. The Anova table shows that the $\mathrm{F}$ value of 7.72 is significant at the .001 level rejecting the $\mathrm{H}: 4$ hypotheses. The result means that $23 \%$ of relation exits among general well being have been significantly explained by the three independent WIS, SIW and Role balance variables.

\section{Discussions}

A number of working students finding paid work or seek different scholarships because many parents have not enough money to pay their children's education expenses. As a result, students are forced to carry on their study as well as their jobs. Both the roles produce conflict between their roles and this conflict aised in the shape of low role balance and general well-being.

In this study, there was a significant negative relationship between work interface with school (WIS), role balance (R.B) and negatively with general well-being. WIS and SIW were significantly co-related with each other because both produced role overload in working students. SIW equally negatively correlated with general well-being and with role balance. Role balance and general well-being of working students are highly significant correlated because when students have high balance between the roles then they have also high wellbeing.

Both SIW and WIS produced pressure which were destructive to the working students and raised emotional strain but many researchers found that role balance moderate this relationship (Marks and MacDermid; Barnett and Hyde, 20011996 Buda and Lenaghan, 2005,).

This study proposed that WIS created more negative role balance as compared to SIW. It means that School work was supportive in the working environment of students. But as compared to conflicting pressure which rose from the SIW, it could be supportive to the individual. The results conclude that SIW perceived as a good or advantageous for some students and some perceived as WIS. It was due to individual differences for example, internship is beneficial and supportive for the students. It depends upon the individual how he/she perceive it.

There were two main findings of this study, first one was that the conflict depends upon the perception of conflict, if WIS or SIW considered as beneficial by the students then their level of role balance and general well-being will be less decreased as compared if he tale role conflict as burden. The second is that the educational expenses increased day by day and to meet this expenses students pay more time in their works, they did not manage the time to give more time for their study. So, the result comes in the shape of absenteeism, turn-out, low grade in exams, increased mistakes and error, resignations and job terminations, reduced productivity, low morale and negative atmosphere and poor employer reputation among staff, customers, and potential new recruits.

The general wellbeing of working students can be enhanced by various methods included different treatments and therapies, for example yoga, hypnotherapy, joy and laughter, mediation, reiki, acupuncture, emotional freedom technique diet and hydration and careful use of drugs. Working students can take proper training for their time management by the university counseling authorities. 


\section{References}

[1] Buda, R. \& Lenaghan, J.A. (2005). Engagement in Multiple Roles: An Investigation of the Student-Work Relationship. The Journal of Behavioral and Applied Management, 6(3), 211-224.

[2] Edwards, J. R. \& Rothbard, N.P. (2000). Mechanisms Linking Work and Family: Clarifying the Relationship Between Work and Family Constructs. Academy of Management Review, 25, 178-199.

[3] Friedman, S. D. \& Greenhaus, J.H. (2000). Work and Family - Allies or Enemies? What happens when business professionals confront life choices? Oxford University Press.

[4] Lightdale, J. R. \& Prentice, D.A. (1994). Rethinking Sex Differences in Aggression Aggressive Behavior in the Absence of Social Roles. Personality \&Social Psychology Bulletin, 20, 30-44.

[5] Bruck, C. S. \& Allen, T.D. (2003). The Relationship Between Big Five Personality Traits, Negative Affectivity, Type A Behavior and Work-family Conflict. Journal of Vocational Behavior, 63, 457-472.

[6] Kopelman, R. E., Greenhaus, J.H. \& Connolly, T.F. (1983). A Model of Work, Family \&Interrole Conflict A Construct Validation Study. Organizational Behavior \&Human Performance, 32, 198-215. Barnett, R.C., Marshall, N.L. \&Pleck,

[7] McDowell, I. \& Newell, C. (1987). The general well-being schedule. In Measuring Health A Guide to Rating Scales \&Questionnaires. Eds I. McDowell \&C. Newell. Oxford University Press, 125-132..

[8] Deckro, G.R., Ballinger, K.M., Hoyt, M., \& Wilcher, M. (May 2002). The evaluation of a mind/body intervention to reduce psychological distress and perceived stress in college students. Journal of American College Health, 50(6), $281-287$.

[9] Neumann, Y., Finaly-Neumann, E., \& Reichel, A. (1990). Determinants and consequences of students' burnout in universities. Journal of Higher Education, 61(1), 20-31.

[10] Vaez, M. \& Laflamme, L. (2003). Health behaviors, self-rated health, and quality of life: A study among first-year Swedish university students. Journal of American College Health, 51,156-161.

[11] Zalenski, E. H., Levey-Thors, C., \& Schiaffino, K. M. (1998). Coping mechanisms, stress, social support, and health problems in college students. Applied Developmental Science, 2 (3), 127-137.

[12] Bruce, S.M., Conaglen, H.M, \& Conaglen, J.V. (2005). Burnout in physicians: A case for peer-support. Internal Medicine Journal, $35,272-278$.

[13] Jenkins, R. \& Elliot, P. (Dee 2004). Stressors, burnout and social support: Nurses in acute mental health settings. Journal of Advanced Nursing, 48(6), 622-631.

[14] Maslach, C., Schaufeli, W.B., \&Leiter, P.M. (2001). Job burnout. Annual Review of Psychology, 53, $397-422$.

[15] Peiro, J.M. , Gonzalez-Roma, V., Tordera, N., \& Manas, M.A. (2001). Does role stress predict burnout over time among health care professionals? Psychology and Health, 16, 511-525.

[16] Duenwald, M. (2002, September 17). Students find another staple of campus life: Stress. The New York Times, p.F5.

[17] Hudd, S.S., Dumlao, J., Erdmann-Sager, D., Murray, D., Phan, E., Soukas, N., \& Yokozuka, N. (2000). Stress at college: effects on health habits, health status and self-esteem. College Student Journal, 34(2), 217-228.

[18] Dixon, W.A. \& Reid, J.K. (Summer 2000). Positive life events as a moderator of stress-related depressive symptoms. Journal of Counseling and Development, 78(3), 343-347.

[19] Frazier, P.A. \& Schauben, L.J. (April 1994). Stressful life events and psychological adjustments among female college students Measurement \& Evaluation in Counseling \& Development, 27(1), 280-293.

[20] Geraghty, M. (August 1997). Campuses see steep increase in students seeking counseling. The Chronicle of Higher Education: Past Chronicle Issues.

[21] Barnett, R.C. and Hyde, J.A. (2001). Women, Men, Work and Family: An Expansionist Theory. American Psychologist, 56, 781 796.

\section{TABLE 1}

Characteristics of the entire sample $(N=80)$

\begin{tabular}{lll}
\hline & $F$ & $\%$ \\
\hline Gender & & \\
Male & 43 & 53.8 \\
Female & 37 & 46.3 \\
Job & 38 & \\
Public & 42 & 47.5 \\
Private & & 52.5 \\
Education & 1 & 1.3 \\
Intermediate & 41 & 51.3 \\
Graduation & 36 & 45.0 \\
Master & 2 & 2.5 \\
M.phil & & \\
Socio Economic status & 13 & 16.3 \\
Low & 31 & 38.8 \\
Middle & 36 & 45.0 \\
High & & \\
\hline
\end{tabular}




\section{Table 2}

Mean, Standard Deviation and Alpha reliability coefficients among work interface with school, School interface with Work, Role Balance, and General well-being $(N=80)$

\begin{tabular}{lcccc}
\hline \multicolumn{1}{c}{ Variables } & No of items & $M$ & $S D$ & $\alpha$ \\
\hline Work Interface With School & 3 & 8.60 & 2.78 & .53 \\
School Interface With Work & 3 & 7.88 & 2.50 & .40 \\
Role Balance & 4 & 13.09 & 3.20 & .53 \\
General Wellbeing & 14 & 40.60 & 8.33 & .69 \\
\hline
\end{tabular}

Table 3

Alpha reliability coefficients and Pearson correlation among work interface with school, School interface with Work, Role Balance, and General well-being $(N=80)$

\begin{tabular}{lcccc}
\hline Variables & 1 & 2 & 3 & 4 \\
\hline 1 Work Interface with School & - & $.45^{* *}$ & $-.26^{*}$ & -.175 \\
2 School Interface with Work & - & - & -.10 & -.10 \\
3 Role Balance & - & - & - & $.48^{* * *}$ \\
4General Wellbeing & - & - & - & -
\end{tabular}

Note, ${ }^{*} p<.05, * * p<.01$

Table 4

Multiple Regression analysis showing the effect of Role Conflict, Role Balance and on General Wellbeing among working students $(N=80)$

\begin{tabular}{lcccc}
\hline Variables & $B$ & $\Delta R^{2}$ & $R^{2}$ & $F$ \\
\hline Work Interface with School & -.04 & 0.20 & .23 & $7.72^{* * * *}$ \\
School Interface with Work & .03 & & & \\
Role Balance & -.47 & & & \\
\hline
\end{tabular}

Note, $* * * p<.001$ 